\title{
Effects of tanshinones mediated by forkhead box O3a transcription factor on the proliferation and apoptosis of lung cancer cells
}

\author{
DONGJIE LIU*, RENBING YUAN*, FANG YANG and DEHUI ZHANG \\ Oncology Department, Daqing Oil Field General Hospital, Daqing, Heilongjiang 163000, P.R. China
}

Received September 4, 2016; Accepted August 8, 2017

DOI: $10.3892 / \mathrm{ol} .2018 .9530$

\begin{abstract}
According to global cancer statistics in 2012, lung cancer (LC) was the most frequently diagnosed cancer and the leading cause of cancer-associated mortality among males worldwide. Owing to the limited therapeutic approaches available, novel methods for treating LC are required. Tanshinones (Ts) have previously been proved to be effective in treating cardiovascular disease, inflammatory disease and cancer, and have been reported to regulate cell proliferation and apoptosis of LC. The underlying molecular mechanism of action of Ts remains unclear. Furthermore, forkhead box O3a (FoxO3a) has been reported to be a critical gene in cell apoptosis. Therefore, the A549 lung cancer cell line was transfected with FoxO3a small interfering RNA (siRNA) or scrambled siRNA, and the cells which exhibited the most successful transfection efficacy were selected for further investigation into the underlying molecular mechanism of the influence of Ts on FoxO3a in LC cells. Various concentrations of Ts were assigned to experimental groups I-IV $(5,10,20$ and $30 \mu \mathrm{mol} / \mathrm{l}$ Ts, respectively). An MTT assay revealed that Ts inhibited cell proliferation in a dose- and time-dependent manner compared with the control group (CON; without Ts administration) with a maximal dose of $20 \mu \mathrm{mol} / 1$ at $72 \mathrm{~h}$ treatment $(\mathrm{P}<0.05)$. Similarly, compared with CON, flow cytometry results revealed that Ts induce LC cell apoptosis in a dose-dependent manner $(\mathrm{P}<0.05)$. Consistently, the expression levels of FoxO3a mRNA and protein were restored following treatment with Ts
\end{abstract}

Correspondence to: Dr Dongjie Liu or Dr Renbing Yuan, Oncology Department, Daqing Oil Field General Hospital, 9 Zhongkang Street, Daqing, Heilongjiang 163000, P.R. China

E-mail: jiedong142@163.com

E-mail: yrenb2236@163.com

*Contributed equally

Abbreviations: LC, lung cancer; Ts, tanshinones; siRNA, small interfering RNA; FoxO3a, forkhead box O3a; ssiRNA, scrambled siRNA; RT-PCR, reverse transcription-polymerase chain reaction

Key words: tanshinones, lung cancer, A549 cells, forkhead box O3a, caspase-3 in a dose-dependent manner, alongside caspase-3 activation. On the basis of these results, we hypothesize that Ts regulate LC cell proliferation and apoptosis by triggering an apoptotic cascade through the FoxO3a/caspase-3 signaling pathway.

\section{Introduction}

According to global cancer statistics in 2012, lung cancer (LC) was the leading cause of cancer-related mortality in developed countries (1). Furthermore, in less-developed countries including China and India, LC rates are predicted to continue increasing as a result of increasing endemic use of tobacco (1). It is well-known that the progression of LC is the result of sequential genetic and epigenetic changes including the dysregulation of oncogenes, tumor suppressor genes and growth factors (2). Currently, the general approach to the treatment of LC (non-small cell LC and small cell LC) is based on surgical resection, chemotherapy and radiation therapy according to the stage (3). However, it is well-known that the intrinsic and potent cytotoxicity to normal cells of a number of anticancer agents imposes a restriction on their prolonged use and their therapeutic effectiveness (4). As a result, exploring novel therapeutic methods is of urgent priority.

Chinese herbs have been considered as novel ways to treat diseases (5). With regard to cancer, a number of previous studies have demonstrated that extractions of specific Chinese herbs exhibit therapeutic effects on certain types of cancer (6-8). The exact underlying molecular mechanism of Chinese medicine-based treatments of cancer remain elusive.

Tanshinones (Ts), including tanshinone I, tanshinone IIA, cryptotanshinone and dihydrotanshinone I, are a class of lipophilic diterpene compounds extracted from Salia miltiorrhiza Bunge, a plant root used in traditional Chinese medicine (9). Numerous studies have demonstrated that Ts exhibit potential properties of anti-inflammation (10), anticancer (11-13) and cardio-cerebrovascular protection (14). Regarding LC, previous studies have suggested that Ts are involved in the process of inhibiting cell proliferation and inducing apoptosis $(13,15,16)$. However, the underlying molecular mechanism of the effect of Ts on LC remains unknown.

Previous studies have demonstrated that FoxO3a, a member of the forkhead box (Fox) gene family of transcription factors, serves a role in the apoptotic cascade $(17,18)$, which suggests that targeting the AMP-activated protein kinase-FoxO3a axis 
is a potential therapeutic approach for cancer treatment (19). Previous study has demonstrated that silencing FoxO3a prevents control of the apoptotic cascade due to the inhibition of mitochondrial membrane depolarization. In contrast, the presence of FoxO3a is the prerequisite for cleaved caspase-3 expression (17). On the basis of these previous studies, we hypothesize that FoxO3a mediates the activity of Ts, regulating LC cell proliferation and apoptosis through caspase-3 activation.

\section{Materials and methods}

Cell lines and cell culture. The human lung cancer cell line A549 was obtained from PeproTech, Inc. (Rocky Hill, NJ, USA). The cells were routinely cultured in Dulbecco's modified Eagle's medium (DMEM; Gibco; Thermo Fisher Scientific, Inc., Waltham, MA, USA) supplemented with $10 \%$ fetal bovine serum (FBS; Thermo Fisher Scientific, Inc.) at $37^{\circ} \mathrm{C}$ in a humidified cell incubator containing $5 \% \mathrm{CO}_{2}$.

Plasmid construction. The plasmid (pMSCV-puro) containing FoxO3a small interfering RNA (siRNA) were constructed by Guangzhou Ribobio Co., Ltd. (Guangzhou, China). The sequences were as follows: siRNA1, 5'-UUCUCCGAACGU GUCACGUTT-3' and 5'-ACGUGACACGUUCGGAGA ATT-3'; siRNA2, 5'-ACUCCGGGUCCAGCUCCACTT-3' and 5'-GUGGAGCUGGACCCGGAGUTT-3'; siRNA3, 5'-GGA ACGUGAUGCUUCGCAATT-3' and 5'-UUGCGAAGC AUCACGUUCCGG-3'. Scrambled siRNA (ssiRNA) was purchased from Invitrogen; Thermo Fisher Scientific, Inc., and with sequences of 5'-CGUUCACGCACCAAUUCUATT-3' and 5'-UAGAAUUGGUGCGUGAACGGA-3'.

Transfection. For transfection, $5 \times 10^{6}$ A549 cells were seeded in 6-well culture plates until reaching $70 \%$ confluence. Subsequently, transfection of cells with recombinant FoxO3a-siRNA/ssiRNA plasmids was performed using Lipofectamine 2000 (Thermo Fisher Scientific, Inc.), according to the manufacturer's protocol. At 8-12 h after transfection, the morphology of transfected cells was observed using a fluorescence microscope (Olympus Corporation, Tokyo, Japan) at x200 magnification, and the most successfully transfected experimental and control (CON) cells were selected to for treatment with Ts in the subsequent experiments.

Preparation of Ts and experimental groups. Ts (Xian Yuensun Biological Technology, Xi'an, Shaanxi, China) were dissolved at $25 \mathrm{mmol} / \mathrm{l}$ in absolute ethyl alcohol and stored at $4^{\circ} \mathrm{C}$ until use. The transfected A549 cells were divided into four groups and treated with Ts as follows: $5 \mu \mathrm{mol} / 1$ Ts (group I), $10 \mu \mathrm{mol} / 1$ Ts (group II), $20 \mu \mathrm{mol} / 1$ Ts (group III), $30 \mu \mathrm{mol} / 1$ Ts (group IV) and the negative control of ssiRNA-transfected cells without Ts administration (CON group).

Measurement of cell proliferation. Cell proliferation was determined using an MTT assay (Shanghai Yeasen Biotechnology Co., Ltd., Shanghai, China), according to the manufacturer's protocol. Transfected A549 cells were seeded onto 96-well plates $\left(5 \times 10^{3}\right.$ cells/well). The cell proliferation was measured every $24 \mathrm{~h}$ for 3 days. The absorbance of cells was screened at $570 \mathrm{~nm}$ using a microplate reader (SM600; Shanghai Utrao Medical Instrument Co., Ltd., Shanghai, China).

Analysis of cell apoptosis. For analysis of apoptosis, the proportions of apoptotic cells were determined using an Annexin V-Fluorescein Isothiocyanate (FITC)/Propidium Iodide (PI) Apoptosis Detection kit (Beijing Solarbio Science and Technology Co., Ltd., Beijing, China), according to the manufacturer's protocol. Briefly, the transfected A549 cells of each group were cultured for $72 \mathrm{~h}$, collected by trypsinization (Beijing Dingguo Changseng Biotechnology Co., Ltd., Beijing, China) and washed with PBS. The cells were subsequently resuspended in $1 \mathrm{X}$ binding buffer at a concentration of $1 \times 10^{6}$ cells $/ \mathrm{ml}$. Subsequently, $5 \mu \mathrm{l}$ Annexin V-FITC was added to the cell suspension, prior to incubation at $4^{\circ} \mathrm{C}$ for $15 \mathrm{~min}$ in darkness. Subsequently, $10 \mu \mathrm{l}$ PI was added to the samples, mixed gently and incubated at $4^{\circ} \mathrm{C}$ for 5 min in darkness. Finally, the cells were screened using flow cytometry (Beckman Coulter, Inc., Brea, CA, USA).

Reverse transcription-polymerase chain reaction (RT-PCR). Total RNA from transfected A549 cells of each experimental group was extracted using TRIzol reagent (Invitrogen; Thermo Fisher Scientific, Inc.). The RT and PCR primers for FoxO3a and GAPDH (internal control) were obtained from KareBay Biochem, Inc. (Monmouth Junction, NJ, USA). The PCR primers for FoxO3a were 5'-CGTGGGTAAAAAGGT GTTCC-3' (forward) and 5'-CAAGCCTCCAAACTCAGG AC-3' (reverse); the primers for GAPDH were 5'-TCGTGG AAGGACTCATGACC-3' (forward) and 5'-AGGGATGAT GTTCTGGAGAG-3' (reverse). The PrimeScript RT Reagent kit (Takara Biotechnology Co., Ltd., Dalian, China) was used to synthesize the first-strand cDNA. The cycling program was as follows: Initiation at $37^{\circ} \mathrm{C}$ for $10 \mathrm{~min}$, followed by $85^{\circ} \mathrm{C}$ for $5 \mathrm{sec}$, then $4^{\circ} \mathrm{C}$ for $10 \mathrm{~min}$. PCR was performed using SYBR Premix Ex Taq (Guangzhou Ribobio Co., Ltd.). Quantitative RT-PCR was performed using the PCR 7900HT Real-Time PCR System (Applied Biosystems; Thermo Fisher Scientific, Inc.). The cycling program was as follows: Initiation at $95^{\circ} \mathrm{C}$ for $30 \mathrm{sec}$, followed by 40 cycles at $95^{\circ} \mathrm{C}$ for $5 \mathrm{sec}$ and at $60^{\circ} \mathrm{C}$ for $34 \mathrm{sec}$. The relative expression level of each circRNA was analyzed using the $\Delta \Delta \mathrm{Cq}$ method (20).

Western blot analysis. The cells of each group were collected, centrifuged $\left(500 \mathrm{x} \mathrm{g}\right.$ at $4^{\circ} \mathrm{C}$ for $\left.15 \mathrm{~min}\right)$ and transferred into clean test tubes. A $400 \mu 1$ volume of lysis buffer (Beyotime Institute of Biotechnology, Haimen, China) was added to each tube to lyse the cells at $-10^{\circ} \mathrm{C}$ for $30 \mathrm{~min}$, then centrifuged at $500 \mathrm{x} \mathrm{g}$ at $4^{\circ} \mathrm{C}$ for $10 \mathrm{~min}$. The formula of the lysis buffer was: Collagenase type IV (1 mg/ml), DNase type I (100 $\mu \mathrm{g} / \mathrm{ml}), \mathrm{CaCl}_{2}$ ( $2 \mathrm{mmol} / \mathrm{l})$ and $\mathrm{MgCl}_{2}(2 \mathrm{mmol} / \mathrm{l})$. The protein concentration of the lysates was examined using the Bradford method (21). Lysates $(200 \mu \mathrm{l})$ were then boiled, electrophoresed (4\% SDS) and transferred onto nitrocellulose membranes (CST Biological Reagents Co., Ltd., Shanghai, China). Non-fat milk solution (10\%) in Tris-buffered saline solution with Tween-20 $(0.5 \mathrm{ml} / \mathrm{l})$ was used to block the membranes, which were incubated at $25^{\circ} \mathrm{C}$ for $2 \mathrm{~h}$. Subsequently, $10 \mu \mathrm{l}$ mouse anti-human FoxO3a monoclonal antibody (cat. no. 05-1075-25UG; 1:250; EMD Millipore, Billerica, MA, USA) and mouse anti-human 
caspase-3 (cat. no. ab1271; 1:1,000; Abcam, Cambridge, UK) were added and incubated at room temperature for $2 \mathrm{~h}$, followed by $5 \mu \mathrm{l}$ alkaline phosphatase-conjugated goat anti-mouse IgG secondary antibody (cat. no. 115-055-006; 1:50; Jackson ImmunoResearch Laboratories, Inc., West Grove, PA, USA). Signals were screened using an automated chemiluminescence immunoassay analyzer (Beckman Coulter, Inc.).

Statistical analysis. All statistical analysis was carried out using the SPSS software package (version 12.0; SPSS, Inc., Chicago, IL, USA) and GraphPad Prism 5.00 software (GraphPad Software, Inc., La Jolla, CA). For comparisons between two groups, Student's t-test was performed. For comparisons between multiple groups, a Student-Newman-Keuls test was performed. $\mathrm{P}<0.05$ was considered to indicate a statistically significant difference.

\section{Results}

Recombinant FoxO3a siRNA and ssiRNA were successfully transfected. The transfected A549 cells expressed green fluorescence as determined using fluorescence microscopy. As presented in Fig. 1, the transfection efficiency of siRNA2 was higher than that of siRNA1 and siRNA3 $(\mathrm{P}<0.05)$, with similar results in comparison with those for a negative control. As a result, siRNA2-transfected cells were selected as the culture containing the most successfully transfected cells to use for further experiments.

Ts inhibit the proliferation of $L C$ cells. To detect cell viability, the absorbance of cells in each group was screened at 24, 48 and $72 \mathrm{~h}$ using an MTT assay. As presented in Fig. 2, Ts inhibited the cell viability in a dose- and time-dependent manner with a maximal dose of $20 \mu \mathrm{mol} / \mathrm{l}$ at $72 \mathrm{~h}$ treatment.

Ts induce LC cell apoptosis. Following treatment of the cells of each group with Ts for $72 \mathrm{~h}$, the effect of Ts was examined using the Annexin V-FITC/PI Apoptosis Detection kit. The proportion of apoptotic cells in each experimental group was increased compared with that of CON $(\mathrm{P}<0.05)$, and dose-dependence was exhibited by experimental groups I-III $(\mathrm{P}<0.05 ;$ Fig. 3). Similarly, no statistically significant difference was identified in experimental groups III and IV, suggesting that $20 \mu \mathrm{mol} / 1$ may be the most appropriate concentration to treat LC cells.

Ts upregulate the expression of FoxO3a mRNA. As presented in Fig. 4A, the expression of FoxO3a mRNA in experimental groups III and IV was increased compared with that of CON $(\mathrm{P}<0.05)$. Similarly, a dose-dependent association was identified in experimental groups I-III, but not in experimental groups III and IV.

Ts modulate FoxO3a and caspase 3. As presented in Fig. 4B and $\mathrm{C}$, compared with the $\mathrm{CON}$ group, the expression of FoxO3a increased as the protein concentration was increased, indicating that FOXO3a was associated with the dosage of Ts in experimental groups I-III $(\mathrm{P}<0.05)$, which was consistent with the results of cell proliferation and apoptosis. Simultaneously, as $\mathrm{FoxO} 3$ a protein was restored, caspase-3 was activated,

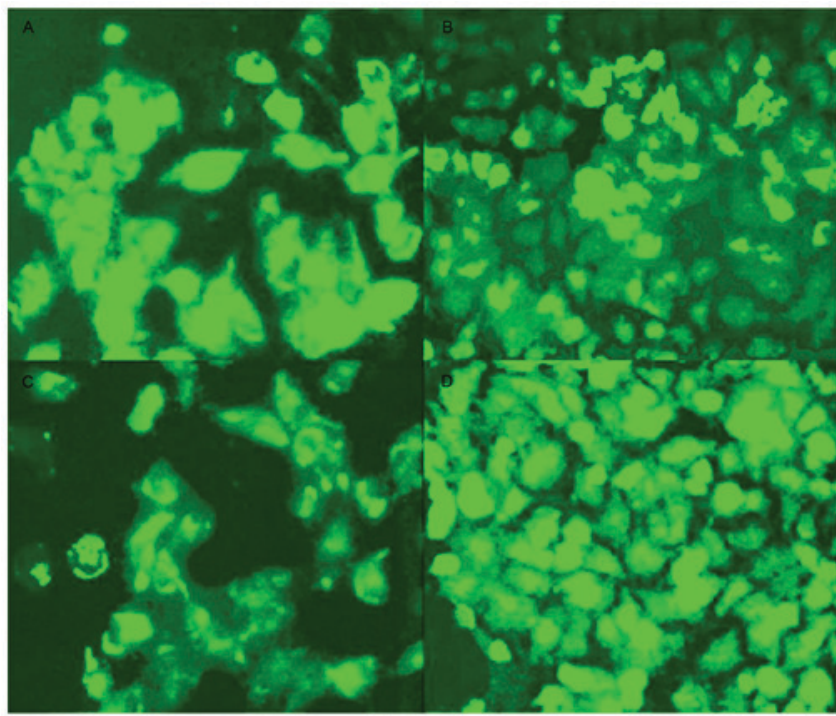

Figure 1. Representative images of transfected A549 cells (magnification, x200). (A) A549 cells were transfected with siRNA1. (B) A549 cells were transfected with siRNA2. (C) A549 cells were transfected with siRNA3 (D) A549 cells were transfected with ssiRNA. siRNA, small interfering RNA; ssiRNA, scrambled siRNA.

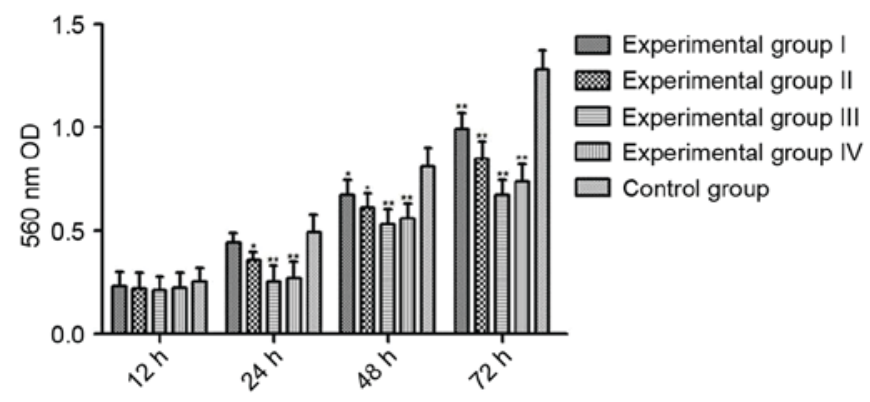

Figure 2. Effect of Ts on the proliferation of transfected A549 cells. Cell proliferation was measured using an MTT assay at various time points. A549 cells were transfected with forkhead box O3a siRNA/ssiRNA, treated with various concentrations of Ts, Groups I-IV were treated with 5, 10, 20 and $30 \mu \mathrm{mol} / 1$ respectively. ${ }^{~} \mathrm{P}<0.05,{ }^{* *} \mathrm{P}<0.01$ vs. control cells treated with ssiRNA. Ts, tanshinones; siRNA, small interfering RNA; ssiRNA, scrambled siRNA; OD, optical density.

suggesting that Ts were able to restore the function of FOXO3a, which governs apoptotic transduction pathways by inducing caspase-3 activity.

\section{Discussion}

FoxO3a has been recognized as a potential tumor suppressor of lung adenocarcinoma, the expression of which is associated with the aggressiveness of the cancer (22-24). Certain Chinese medicines, including berberine, have been demonstrated to contribute to the inhibition of LC cell proliferation and the induction of apoptosis by regulating the expression of FoxO3a, which serves a role in the activation of the p38a mitogenactivated protein kinase signaling pathway (25). Although the results of previous studies suggest that Ts are implicated in anticancer activities including dysregulation of cell proliferation, apoptosis, cell cycle arrest, metastasis, differentiation and angiogenesis $(15,16,26-28)$, the underlying molecular 
A

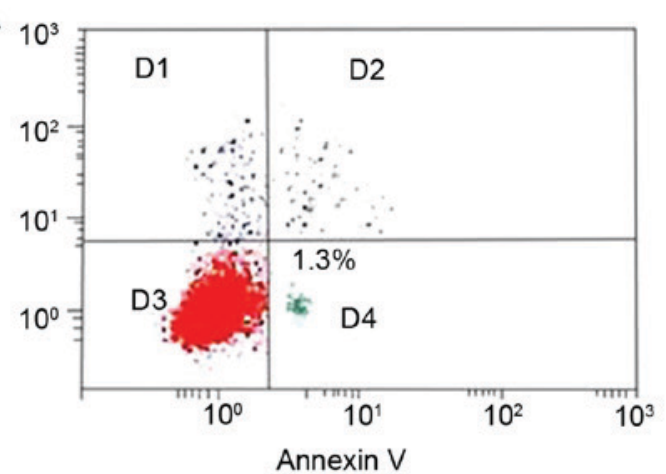

C

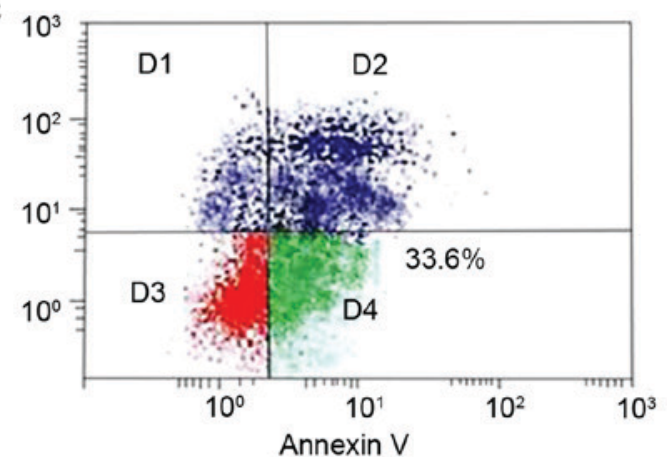

$\mathrm{E}$

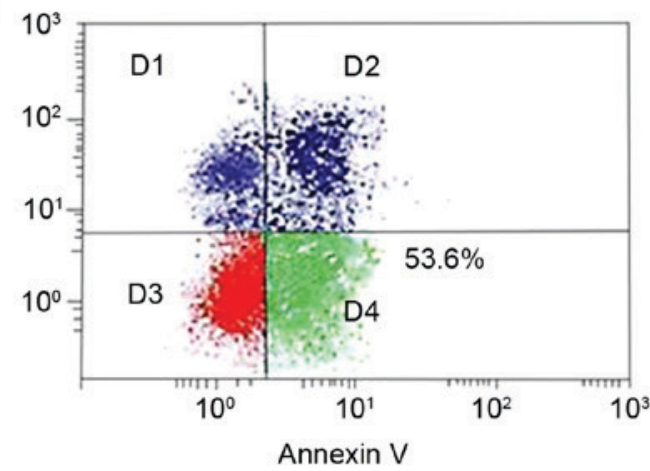

B

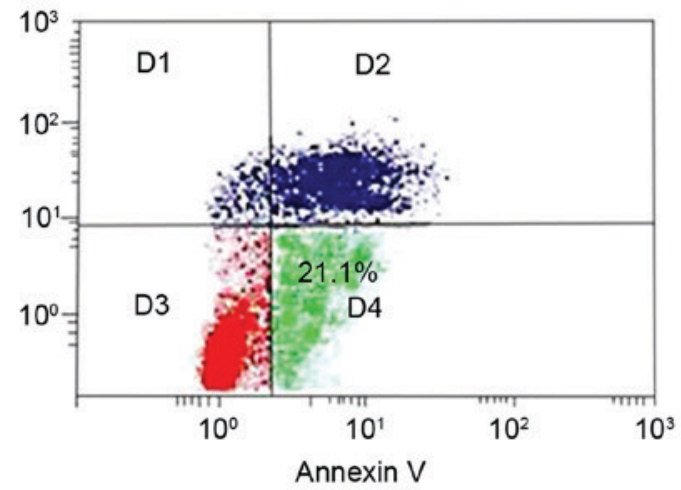

D

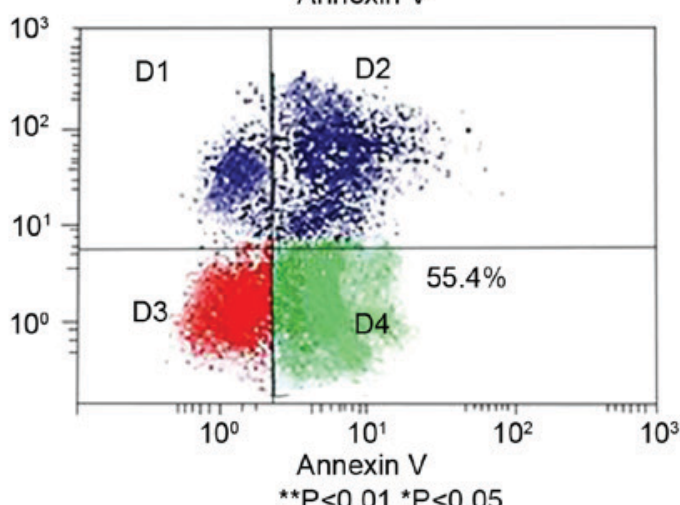

$\mathrm{F}$

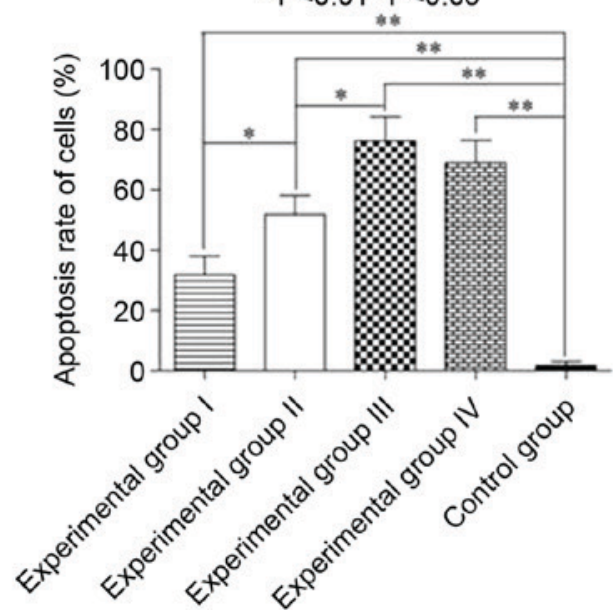

Figure 3. Effect of Ts on cell apoptosis. (A) Control group. (B) Experimental group I treated with Ts. (C) Experimental group II. (D) Experimental group III. (E) Experimental group IV. (F) Apoptotic rate of experimental groups. ${ }^{*} \mathrm{P}<0.05,{ }^{* *} \mathrm{P}<0.01$ vs. control group. Ts, tanshinones.

mechanism remains unknown. As a result, the aim of the present study on LC cell treatment with Ts was to investigate the potential signaling pathway mediated by FoxO3a.

To address the aforementioned questions, effective transfected LC cells were established by silencing FoxO3a, whereas the CON cells transfected with FoxO3a ssiRNA retained intact FoxO3a in LC cells. In addition, construction of the siRNA nucleotide sequence was optimized with processes including the presence of a phosphate group at the 5'-terminus and the strand with a less stable 5'-end (29). The successful knockdown of FoxO3a provided a good foundation for the subsequent experiments.

Dysregulation of cell proliferation is the critical characteristic of LC, therefore four distinct concentrations of Ts $(5,10,20$ and $30 \mu \mathrm{mol} / \mathrm{l})$ were used to treat the experimental groups. The absorbance of experimental groups with FoxO3a knockdown decreased in a dose- and time-dependent manner when compared with that of $\mathrm{CON}$, excluding the concentration of $30 \mu \mathrm{mol} / 1$, which indicates that Ts inhibit LC cell proliferation. Additionally, the results demonstrated that the optimal cell inhibition ratio was with $20 \mu \mathrm{mol} / 1$ at $72 \mathrm{~h}$, so subsequent measurements were made at the $72 \mathrm{~h}$ time point.

Circumventing of cell apoptosis is another feature of LC. In accordance with a previous study of the effect of Ts on LC (15), the results of the present study illustrated that Ts induce cell apoptosis in a dose-dependent manner; however, experimental group IV did not continue the trend of dose-dependence. Cells transfected with non-specific scrambled siRNA without Ts did not exhibit markedly early and late programs of apoptosis. In contrast, experimental groups demonstrated increased proportions of apoptotic cells, identifying the unique ability of Ts to control the early and late apoptotic programs. 

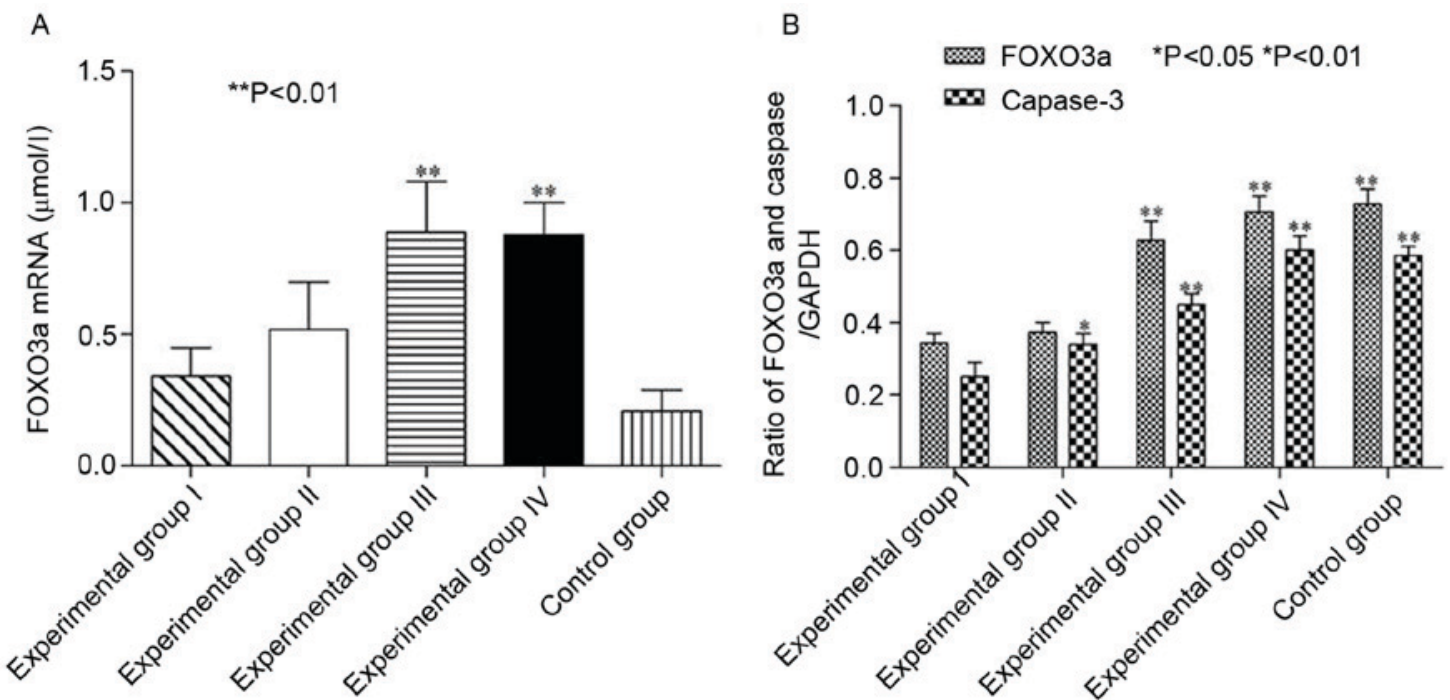

C

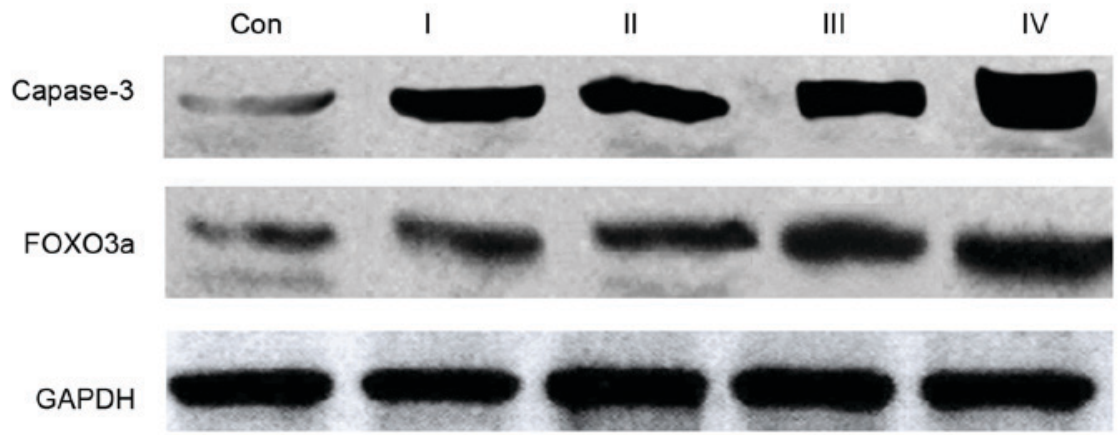

Figure 4. Expression of FoxO3a mRNA and protein. (A) The expression of FoxO3a mRNA was upregulated following a dose-dependent association. (B) The ratio of FOXO3a and caspase-3/GAPDH. (C) Images of GAPDH, FoxO3a and caspase-3 for western blot analysis. ${ }^{*} \mathrm{P}<0.05$, ${ }^{* *} \mathrm{P}<0.01$ vs. control group. FoxO3a, forkhead box O3a; CON, control.

Furthermore, the results of the present study demonstrated that the expression levels of FoxO3a protein in cells treated with Ts were increased compared with those in CON cells, consistent with the expression of FoxO3a mRNA with RT-PCR. Previous studies have demonstrated that silencing FoxO3a depletes the induction of caspase-3 activity (30). The results of the present study support this hypothesis by restoring the expression of FoxO3a with Ts treatment, inducing apoptosis by activating a downstream molecule, caspase-3.

The results of the present study reveal that Ts may serve a direct role in regulating LC cell proliferation and apoptosis, mediated by FoxO3a activation; however, further studies are required to determine the exact signaling pathways mediated by Ts. Addressing this deficit in our knowledge may lead to novel therapeutic approaches to treat LC clinically.

\section{Acknowledgements}

The authors would like to thank Dr. Zhuang Yongzhi, chief physician of Daqing Oilfield General Hospital, and chief surgeon Dr. Zhou Daming of the Oncology Department of Daqing Oilfield General Hospital for their guidance in the present research. The authors would also like to thank Dr. Zhang Liangyu, deputy chief physician of the Oncology Department of Daqing Oilfield General Hospital for their help and support.

\section{Funding}

No funding was received.

\section{Availability of data and materials}

The datasets used and/or analyzed during the current study are available from the corresponding author on reasonable request.

\section{Authors' contributions}

DJL, FY and DHZ made substantial contributions to conception and design, RBY analysis and interpretation of data. DJL agreed to be accountable for all aspects of the work in ensuring that questions related to the accuracy or integrity of any part of the work are appropriately investigated and resolved.

\section{Ethics approval and consent to participate}

Not applicable.

\section{Consent for publication}

Not applicable. 


\section{Competing interests}

The authors declare that they have no competing interests.

\section{References}

1. Torre LA, Bray F, Siegel RL, Ferlay J, Lortet-Tieulent J and Jemal A: Global cancer statistics, 2012. CA Cancer J Clin 65 87-108, 2015

2. Hirsch FR, Franklin WA, Gazdar AF and Bunn PA Jr: Early detection of lung cancer: Clinical perspectives of recent advances in biology and radiology. Clin Cancer Res 7: 5-22, 2001.

3. Spira A and Ettinger DS: Multidisciplinary management of lung cancer. N Engl J Med 350: 379-392, 2004.

4. Ho C, Ramsden K, Zhai Y, Murray N, Sun S, Melosky B and Laskin J: Less toxic chemotherapy improves uptake of all lines of chemotherapy in advanced non-small-cell lung cancer: A 10-year retrospective population-based review. J Thorac Oncol 9: 1180-1186, 2014.

5. van der Greef J: Perspective: All systems go. Nature 480: S87, 2011.

6. Wu J, Tang Q, Zhao S, Zheng F, Wu Y, Tang G and Hahn SS: Extracellular signal-regulated kinase signaling-mediated induction and interaction of $\mathrm{FOXO} 3 \mathrm{a}$ and p53 contribute to the inhibition of nasopharyngeal carcinoma cell growth by curcumin Int J Oncol 45: 95-103, 2014.

7. Jiang WG, Ye L, Ji K, Frewer N, Ji J and Mason MD: Inhibitory effects of Yangzheng Xiaoji on angiogenesis and the role of the focal adhesion kinase pathway. Int J Oncol 41: 1635-1642, 2012.

8. Gao L, Li Q, Jiang M, Liu C, Song Z, Bao X, Shen Y, Liu G and $\mathrm{Hu} \mathrm{K}$ : Combined therapy of percutaneous cryoablation and traditional Chinese medicine can be a promising strategy for elderly or advanced lung cancer patients based on a retrospective clinical study. Cryobiology 69: 174-177, 2014.

9. Zhou L, Zuo Z and Chow MS: Danshen: An overview of its chemistry, pharmacology, pharmacokinetics, and clinical use. J Clin Pharmacol 45: 1345-1359, 2005.

10. Zheng S, Ren Z, Zhang Y and Qiao Y: Anti-inflammatory mechanism research of tanshinone II A by module-based network analysis. Biomed Mater Eng 24: 3815-3824, 2014.

11. Su CC, Chen GW and Lin JG: Growth inhibition and apoptosis induction by tanshinone I in human colon cancer Colo 205 cells. Int J Mol Med 22: 613-618, 2008.

12. Gong Y, Li Y, Abdolmaleky HM, Li L and Zhou JR: Tanshinones inhibit the growth of breast cancer cells through epigenetic modification of Aurora A expression and function. PLoS One 7: e33656, 2012.

13. Li Y, Gong Y, Li L, Abdolmaleky HM and Zhou JR: Bioactive tanshinone I inhibits the growth of lung cancer in part via downregulation of Aurora A function. Mol Carcinog 52: 535-543, 2013.

14. Shang Q, Xu H and Huang L: Tanshinone IIA: A promising natural cardioprotective agent. Evid Based Complement Alternat Med 2012: 716459, 2012.
15. Chiu TL and Su CC: Tanshinone IIA induces apoptosis in human lung cancer A549 cells through the induction of reactive oxygen species and decreasing the mitochondrial membrane potential. Int J Mol Med 25: 231-236, 2010.

16. Lee CY, Sher HF, Chen HW, Liu CC, Chen CH, Lin CS, Yang PC, Tsay HS and Chen JJ: Anticancer effects of tanshinone I in human non-small cell lung cancer. Mol Cancer Ther 7: 3527-3538, 2008.

17. Hou J, Chong ZZ, Shang YC and Maiese K: FOXO3a governs early and late apoptotic endothelial programs during elevated glucose through mitochondrial and caspase signaling. Mol Cell Endocrinol 321: 194-206, 2010.

18. Zhao GX, Xu LH, Pan H, Lin QR, Huang MY, Cai JY, Ouyang DY and He XH: The BH3-mimetic gossypol and noncytotoxic doses of valproic acid induce apoptosis by suppressing cyclin-A2/Akt/FOXO3a signaling. Oncotarget 6: 38952-38966, 2015.

19. Chiacchiera F and Simone C: The AMPK-FoxO3A axis as a target for cancer treatment. Cell Cycle 9: 1091-1096, 2010.

20. Livak KJ and Schmittgen TD: Analysis of relative gene expression data using real-time quantitative PCR and the 2(-Delta Delta C(T)) method. Methods 25: 402-408, 2001.

21. Kruger NJ: The bradford method for protein quantitation. Methods Mol Biol 32: 9-15, 1994.

22. Herzog CR, Blake DC Jr, Mikse OR, Grigoryeva LS and Gundermann EL: FoxO3a gene is a target of deletion in mouse lung adenocarcinoma. Oncol Rep 22: 837-843, 2009.

23. Blake DC Jr, Mikse OR, Freeman WM and Herzog CR: FOXO3a elicits a pro-apoptotic transcription program and cellular response to human lung carcinogen nicotine-derived nitrosaminoketone (NNK). Lung Cancer 67: 37-47, 2010

24. Liu HB, Gao XX, Zhang Q, Liu J, Cui Y, Zhu Y and Liu YF: Expression and prognostic implications of FOXO3a and Ki67 in lung adenocarcinomas. Asian Pac J Cancer Prev 16: 1443-1448, 2015.

25. Zheng F, Tang Q, Wu J, Zhao S, Liang Z, Li L, Wu W and Hann S: p38 $\alpha$ MAPK-mediated induction and interaction of FOXO3a and p53 contribute to the inhibited-growth and induced-apoptosis of human lung adenocarcinoma cells by berberine. J Exp Clin Cancer Res 33: 36, 2014.

26. Ho TF and Chang CC: A promising 'TRAIL' of tanshinones for cancer therapy. Biomedicine (Taipei) 5: 23, 2015.

27. Ma ZL, Zhang BJ, Wang DT, Li X, Wei JL, Zhao BT, Jin Y, Li YL and Jin YX: Tanshinones suppress AURKA through up-regulation of miR-32 expression in non-small cell lung cancer. Oncotarget 6: 20111-20120,2015.

28. Gao H, Sun W, Zhao W, Hao W, Leung CH, Lu J and Chen X: Total tanshinones-induced apoptosis and autophagy via reactive oxygen species in lung cancer 95D cells. Am J Chin Med 43: 1265-1279, 2015

29. Alagia A and Eritja R: siRNA and RNAi optimization. Wiley Interdiscip Rev RNA 7: 316-329, 2016.

30. Shang YC, Chong ZZ, Hou J and Maiese K: The forkhead transcription factor FOXO3a controls microglial inflammatory activation and eventual apoptotic injury through caspase 3. Curr Neurovasc Res 6: 20-31,2009. 